\title{
Projecting long-term armed conflict risk: An underappreciated field of inquiry?
}

\author{
Sophie P. de Bruin ${ }^{\text {a,b, }}$, Jannis M. Hoch ${ }^{a}$, Nina von Uexkull ${ }^{c}$, Halvard Buhaug ${ }^{\mathrm{d}, \mathrm{e}}$, \\ Jolle Demmers ${ }^{\mathrm{f}}$, Hans Visser ${ }^{\mathrm{b}}$, Niko Wanders ${ }^{\mathrm{a}}$ \\ a Department of Physical Geography, Utrecht University, Princetonlaan 8A, 3508 CB Utrecht, the Netherlands \\ ${ }^{\mathrm{b}}$ PBL Netherlands Environmental Assessment Agency, Bezuidenhoutseweg 30, The Hague 2594 AV, the Netherlands \\ ${ }^{\mathrm{c}}$ Department of Peace and Conflict Research, Uppsala University, Box 514, SE-751 20 Uppsala, Sweden \\ d Peace Research Institute Oslo, Hausmanns Gate 3, 0186 Oslo, Norway \\ e Department of Sociology and Political Science, Norwegian University of Science and Technology, NO-7491 Trondheim, Norway \\ ${ }^{\mathrm{f}}$ Conflict Studies and History of International Relations, Faculty of Humanities, Utrecht University, Drift 10, 3512 BS Utrecht, the Netherlands
}

\section{A R T I C L E I N F O}

\section{Keywords}

Climate change

Future armed conflict

Scenario development

Science-policy interface

\begin{abstract}
A B S T R A C T
Little research has been done on projecting long-term conflict risks. Such projections are currently neither included in the development of socioeconomic scenarios or climate change impact assessments nor part of global agenda-setting policy processes. In contrast, in other fields of inquiry, long-term projections and scenario studies are established and relevant for both strategical agenda-setting and applied policies. Although making projections of armed conflict risk in response to climate change is surrounded by uncertainty, there are good reasons to further develop such scenario-based projections. In this perspective article we discuss why quantifying implications of climate change for future armed conflict risk is inherently uncertain, but necessary for shaping sustainable future policy agendas. We argue that both quantitative and qualitative projections can have a purpose in future climate change impact assessments and put out the challenges this poses for future research.
\end{abstract}

\section{Introduction}

How will climate change affect armed conflict in the long-term future? Which regions will face increased risk, following what sudden events and underlying grievances? We do not know. We can, however, picture various plausible futures, which correspond to different scenarios of socio-economic and environmental change. But while scenario development has advanced in the context of climate change (IPCC, 2018, IPCC, 2019), the environment (Ahmadalipour et al., 2019, Doelman et al., 2018) and socio-economic conditions (Rao et al., 2019, Dellink et al., 2017, van Meijl et al., 2020), there have been few attempts to develop scenario-based armed conflict risk projections in response to these various scenarios (von Uexkull and Buhaug, 2021). Against the backdrop of emerging scenario development in climate, environmental, economic and demographic fields that gained significant political authority from the 1970's onwards (Raskin et al., 2005), the prevalence of long-term armed conflict risk projections to support policy-making is limited. This gap is worrying, especially in the light of climate change impacts having a two-way interaction with conflict. On the one hand because climate change could affect the likelihood and prevalence of armed conflict through its impacts on conditions that are known to increase conflict risk, such as loss of income and frustration over poor governance responses (Mach et al., 2019, Koubi, 2019). On the other hand because social trade-offs of climate change are sensitive to armed conflict, such as poverty, health issues and hunger (Gates et al., 2012). Thereby, the outbreak of armed conflict can obstruct climate mitigation and adaptation efforts by weakening governance structures and by increasing environmental degradation (Landholm et al., 2019, Schillinger et al., 2020). In other words, we miss a lot if we project long-term socio-economic and climate change impacts and implicitly assume that the future will be peaceful.

While methodological development and policy-uptake of long-term conflict risk projections in response to climate change is mostly absent, the potential role of climate variability or climate change impacts for the historical onset and intensity of armed conflict has received increasing attention in recent years, in both scientific and political communities (Koubi, 2019, Mach et al., 2019, von Uexkull and Buhaug, 2021, UNSC, 2017). This increased attention has resulted in a growing

\footnotetext{
* Corresponding author at: PBL Netherlands Environmental Assessment Agency, Bezuidenhoutseweg 30, The Hague 2594 AV, the Netherlands.

E-mail address: Sophie.debruin@pbl.nl (S.P. de Bruin).
} 
body of evidence on historical climate and conflict interactions, primarily directed at armed conflict within countries (von Uexkull and Buhaug, 2021). This evidence has hitherto hardly translated in academic efforts to identify future regions-at-risk in a context of climate change, with Witmer et al. (2017) being one of the few studies that addresses this research gap. This seems surprising since it is likely that worsening impacts of climate change will increase future conflict risk via different pathways in the absence of successful adaptation (Mach et al., 2019).

The construction and exploration of different alternative futures can contribute to much needed insights for policy (Mach and Kraan, 2021, Maier et al., 2016). The goal of future scenario assessment is not to gain knowledge on what is likely to happen in the 'foreseeable' future with a high level of accuracy, as it is in short-term prediction or forecasting, but rather to trigger deliberations about possible futures and, in turn, to provide a starting point for interventions and adaptive policy options with the long-term perspective in mind (Mahmoud et al., 2009, Raskin et al., 2005). Scenario-based conflict risk projections linked to climate change could serve this goal and, more specifically, improve scientific impact assessments of climate change and could highlight security implications of alternative policy decisions concerning climate mitigation and societal development. Moreover, conflict projections can serve as valuable input to projections of other socio-economic outcomes that historically are sensitive to conflict, such as prevalence of undernourishment and forced displacement (Buhaug and Vestby, 2019).

In this perspective article we discuss why scenario-based conflict risk projections are largely missing in academia and policy, and why we deem this problematic, specifically in the context of climate change. We do this by first briefly discussing recent advances in short-term and longterm conflict risk analyses in general, followed by a deliberation on the causes for limited scientific progress in long-term conflict risk projections. This perspective continues with a discussion on how such projections would be useful for policy and science, and closes by outlining future research directions of this field.

\section{Recent advances in short-term predictions and long-term projections}

Different from long-term armed conflict projection developments, the scientific efforts and application of short-term prediction and early warning systems have advanced considerably due to new approaches and methods (Cederman and Weidmann, 2017, Muchlinski et al., 2016). We have recently seen the development of a variety of new conflict early warning systems, such as the West Africa Early Warning and Early Response Network (WANEP, 2021); the EU conflict Early Warning System (European Commission, 2019); the Water, Peace and Security Tool (WPS, 2021) and the Violence Early-Warning System ViEWS (Hegre et al., 2019).

Currently, these early warning systems are neither extended nor complemented with long-term risk projections in general, let alone paying attention to the long-term risks following climate change impacts. Separately, a few studies have explored the potential of long-term conflict projections: Hegre et al. (2013) developed a statistical model for internal armed conflict over the period 1970-2009 to forecast conflict towards 2050 (reviewed by Hegre et al. (2021)); Hegre et al. (2016) offer internal armed conflict projections towards 2100 following quantifications of the storylines of the Shared Socio-economic Pathways (SSPs); Joshi et al. (2015) and Hughes et al. (2014) utilise the International Futures model to provide long-term conflict risk projections; Witmer et al. (2017) forecast subnational patterns of future violence in Africa, making use of socio-economic developments together with climate anomalies; and Hoch et al. (2021) applies a machine learning approach to project conflict risk based on three SSPs and corresponding hydroclimatic conditions. Nevertheless, these handful long-term projections are not yet applied in policy-related risk assessments and policy development processes in the same manner as various early-warning frameworks.

\section{Why is there so little emphasis on long-term conflict projections?}

The limited scientific progress in long-term conflict projections can be roughly attributed to two causes. The first and most prominent cause can be found in the methodological difficulties to specify the configurations of relevant causal mechanisms and processes that explain the outbreak of armed conflict across contexts due to its volatile and complex nature (Gartzke, 1999). The potential but ambiguous role of climate change in armed conflict only complicates this challenge. While research has made some progress, there are still central knowledge gaps with regards to the mechanisms and conditions through which climate change impacts conflict risk (Mach et al. 2019; Von Uexkull \& Buhaug 2021). The second cause refers to the seemingly restricted applicability of conflict risk projections in response to climate change for policy. These two factors mutually influence each other: lack of interest from policy makers limits an impulse for scientific funds and consequently efforts to demonstrate and strengthen the merit of such projections for policy actors. The following paragraphs elaborate on each of these explanations.

The methodological difficulties limiting scientific progress originate from five major complications that link primarily to the quantitative modelling of conflict risks in response to climate change. First, internal armed conflict is typically caused by a wide combination of different factors on different spatial and temporal levels, ranging from lacking opportunities to socio-economic divisions, including inequalities between ethnic groups to governance or power issues (see overviews in Blattman and Miguel (2010), Cederman et al. (2013), Hegre and Sambanis (2006)). When it comes to conflict projections in response to climate change, an additional challenge is the often weak and unstable empirical estimates of present associations (Koubi, 2019). To make sure the 'right' indicators are captured in modelling these long-term risks, evaluating model performance in predicting out-of-sample conflict is essential (Hegre et al., 2021). Second, even if new machine learning techniques are able to grasp the complex dynamics in underlying data, systemic geopolitical shifts (e.g. fall of the Berlin Wall; the Arab Spring; future governance of climate crisis; territorial shifts) with lasting impact on the baseline of conflict risk, are hard, or even impossible to include in long-term projections (Cederman, 1997). The possibility of geopolitical shifts could be incorporated into scenario assumptions about future developments, although this would substantially increase uncertainty as well as the number of possible futures. Third, some empirical observations and interpretations are difficult or even impossible to quantify, such as dynamics resulting from local cultural traditions, identity group formation, or historically-specific processes or ideas. This limits quantification of possible drivers of conflict, restricting model developments (Demmers, 2017, Cramer, 2006). Though, this limitation is arguably especially important in accurately forecasting armed conflict and to a lesser extent for long-term conflict risk projections in response to climate change. Fourth, data-related uncertainties and definitions affect the outcome and reliability of modelling conflict risk. On the one hand since some empirical results have been shown to be sensitive to the definition and operationalisation of armed conflict (Hegre and Sambanis, 2006). On the other hand since obtaining high-quality data of underlying societal conditions that could explain the outbreak of violence is often challenging in conflict-prone regions (Visser et al., 2020). These data issues further increase uncertainty when quantifying drivers of conflict. And last, the interplay between the assumed drivers of conflict may not be constant over time, but depend on the specific context (Bowlsby et al., 2019), making it challenging to take historical relations as a fixed basis for long-term projections. The potential indirect and direct security impacts of climate change may in particular become more prominent when these impacts worsen (Mach et al. 2019).

The second, more speculative cause of the limited scientific progress of long-term conflict risk projections relates to their perceived limited applicability or merit in decision-making processes. The nature of 
conflict resolution and peace building is mostly reactive and setting long-term goals that serve as a benchmark for policies and interventions is not common. While Integrated Assessments Models (IAMs) have become policy relevant as a result of their capability to meet emerging knowledge demands on behalf of the policy community (van Beek et al., 2020, Mach and Kraan, 2021), there seems to be no such demand for knowledge and benchmarking in the global security community. The adoption of Sustainable Development Goal 16 - promote just, peaceful and inclusive societies - marks the first time that violence and conflict are being addressed in a dedicated global development goal (EPRS, 2020). However, this qualitative medium-term (2015-2030) global goal has not yet led to an increased demand for conflict risk projections that could inform actions for different scenarios.

Although there seems to be neither rising nor urgent demand for quantitative conflict risk projections in working towards global goals, countries and international organisations make use of non-academic long-term strategic foresights and qualitative scenario studies. The publicly available studies are for example used to sketch long-term societal processes or military technology developments (Muzalevsky, 2017, Lucarelli et al., 2014). Thereby is it likely that non-public scenario studies inform and prepare strategic military operations and stationing. Climate change begins to play a role in these strategic foresights, not only in terms of perceived security risks, but also in terms of climaterelated vulnerabilities of people, material or infrastructure to for example flooding and melting permafrost (Department of Defence USA, 2019, Gemenne et al., 2020). However, the goal in these foresights is not to come to a shared global understanding nor to develop perspectives for action on the way forward, but rather to serve the interests of individual actors.

\section{What are useful and necessary purposes for long-term conflict risk projections?}

To advance scientific progress and the policy relevance of long-term conflict risk projections, specifically in response to climate change, defining the possible purposes of these projections is an important first step. We identify three possible and related purposes: first, highlighting regions at particular risk that deserve attention in conflict-sensitive climate adaptation and conflict prevention efforts; second, spurring discussion between different actors stimulating a shared understanding of short- and long-term risks; and third, better integrating conflict risk in the wider field of scenario advances for sustainable development in general and climate change more specifically.

Long-term conflict risk projections in response to climate change could serve conflict prevention and conflict-sensitive climate adaptation efforts implemented by individual countries, non-governmental organisation or intergovernmental bodies, and unions of countries. Policy design for conflict prevention such as the Instrument for Stability and Peace at the EU level, involves longer-term processes and annual decision cycles, supporting inter alia socio-economic development through aid programs and diplomacy. These processes could be improved by adopting a long-term perspective on possible futures of conflict in relation to climate change. Additionally, for climate adaptation to be effective and inclusive, the wider potential social and ecological context and possible societal effects should be considered, in the present and in the future (Eriksen et al., 2011). In regions with high conflict risks, these effects can be different than in regions facing low conflict risk.

A second purpose, in line with the first, is the creation of a mutual understanding between researchers and decision-makers about imaginable intersecting long-term climate risks and short-term interests. Facilitating discussions between policymakers on projections can lead to a better understanding of what information is needed from the modelling community to support well-informed long-term policies (Muhonen et al., 2020, van Beek et al., 2020). This process can also contribute to a balance between actors' short- and medium-term interests and longterm developments (Jones et al., 2017). By bringing policymakers together to discuss possible long-term developments beyond reactions to urgent crises, these insights can contribute to improved policies.

A last useful and necessary purpose is the consolidation of socioeconomic and environmental scenario development with conflict risk. Even though the outbreak of conflict diminishes progress in economic, educational and environmental efforts (Gates et al., 2012), long-term scenarios in these fields are yet to incorporate adverse impacts of future armed conflict (Buhaug and Vestby, 2019). Including projections of conflict risk particularly related to climate change impacts in the wider agenda of long-term human development would provide a more complete picture of potential issues and set-backs (Gilmore et al., 2021 unpublished). This would also require the development of long-term scenario projections addressing the potential effects of climate change impacts on human development. Conflict risk is only one of the many not well-understood possible consequences of climate change impacts. A limited set of long-term scenario projection studies are already available assessing the human development impacts of climate change on inter alia vulnerability to poverty (Byers et al., 2018), internal migration (Rigaud et al., 2018) and compound vulnerabilities to climate change impacts (Busby et al., 2014). However, a more comprehensive understanding of the diverse and likely interacting human development impacts is urgently needed. Potential conflict risks and related human development challenges in a climate-stressed world require a pro-active approach building on long-term strategies, most prominently in regions with high climate vulnerability and limited governance capacities (Busby et al., 2014). Long-term conflict risk projections in response to various socio-economic and environmental scenarios can be a valuable tool to inform decision-makers about implications of alternative policy choices related to adaptation, mitigation, and sustainable development.

\section{Future research directions}

We see the scarcity of long-term conflict risk projections in response to climate change as an important research gap. Such projections should guide future research to inform various long-term policies and to integrate conflict risk in sustainable development scenarios and impacts assessments of climate change. Both the development of quantitative models as well as expert elicitation and qualitative scenario development can fill this gap, ideally together with each other, since there is not one approach 'to rule them all' - that is, can overcome all methodological difficulties addressed.

Methodological progress in Machine Learning (ML) and Artificial Intelligence (AI) techniques may be able to better grasp the complex dynamics leading to conflict and deal with imbalanced data availability (Colaresi and Mahmood, 2017, Muchlinski et al., 2016, Hoch et al., 2021). These quantitative data-driven methods can handle non-linear and often complex nature of conflict processes and contribute to a better understanding of conflict drivers. The resulting insights can then be the basis for conflict risk projections, in interplay with diverging trends of social, economic, political and environmental conditions. A major disadvantage of ML is the limited understanding it gives with regard to better understanding the underlying mechanisms leading to conflict, due to their 'black box' nature. However, new methods arise in making ML models more interpretable. Techniques such as partial dependence plots and feature importance functions are given in detail by Molnar (2021).

Besides methodological progress in $\mathrm{ML}$ and $\mathrm{AI}$ techniques, the quantitative dimension of projecting long-term conflict risk could advance by the development of enhanced scenarios, by including negative feedbacks resulting from conflict on socio-economic development (Gilmore et al., 2021 unpublished). Existing socio-economic and political scenario projections, such as quality of governance (Andrijevic et al., 2020) and economic development (Dellink et al., 2017), very likely over-estimate future growth in developing countries due to an inability to account for common disruptive forces, such as political instability and armed conflict (Buhaug and Vestby, 2019). Since 
governance and economic growth are important factors shaping the likelihood and duration of conflict (Mach et al., 2019), these positive projections imply almost automatically a more peaceful future when following these storylines, as is the case in.

Qualitative insights based on expert judgement and field experiences are essential to the development of this field, to account for the methodological difficulties of quantitative approaches. We provide four arguments. First, qualitative methods can capture highly disruptive events affecting conflict risk which are currently not part of the quantified pathways in the SSPs. Illustrative is the provocative argumentation of Nassim Taleb about the potentially enormous impacts of a highly improbable event (Taleb, 2010). Qualitative foresight analysis is much better suited to include highly dystopic futures than conventional quantitative scenario frameworks, such as that provided by the SSPs. For example, what security risks could follow from a situation in which almost $20 \%$ of the earth's land surface would become uninhabitable for humans, as pictured by Xu et al. (2020)? Second, qualitative approaches are important to interpret the plausibility of quantitative scenarios when integrating long-term risk profiles into policies. Third, qualitative expert assessments can help to address the fact that historical relations and interactions driving conflict risk are shown to be unstable over time (Bowlsby et al., 2019). And last, qualitative methods can facilitate the inclusion of the valuable on-the-ground experiences of diplomats, peacekeeping missions and non-governmental organisations in identifying context-specific solution pathways.

Future directions of research should not be limited to exploring conflict risk implications of alternative climate change and societal development pathways. The research community should also aid the utilisation of new insights by policy-makers. To this end, scientists and end users in policy and practice need to go through a process of cocreation where conflict projections are developed and improved in concerted actions, based on the needs of the users and the possibilities provided by science (Muhonen et al., 2020, van Beek et al., 2020). Here, qualitative and quantitative scenario insights should be combined to gain confidence, reliability and trust in these insights, and for becoming policy-relevant.

\section{Concluding remarks}

Today, long-term projections of conflict risk in response to climate change are not widely available. This is primarily the result of methodological difficulties, which might explain their underappreciation in policy communities and in socio-economic scenarios and climate change impact assessments. As long as there are hardly any studies on conflict risk projections, they are unlikely to be used in policy agendas, wider socio-economic scenarios or climate change impact assessments. The scientific community should take up the challenge to improve quantitative and qualitative long-term conflict risk projections linked to climate change. Although improving knowledge on future armed conflict-driver interactions and data availability provides challenges, especially with regard to the magnitude of climate change impacts, combining insights from qualitative and quantitative risk assessments is a viable way forward. This should be the start of an iterative cycle on the interface of science and policy that will ultimately lead to improved reliability and usability of the much-needed future conflict risk projections.

\section{Author contributions}

SdB designed this study, developed the methodology and performed the analysis, JH and NW supported the methodology development and analysis. NW acquired the funds for this project. All authors contributed to the scientific discussion, writing and proof-reading of the manuscript.

\section{Declaration of Competing Interest}

The authors declare that they have no known competing financial interests or personal relationships that could have appeared to influence the work reported in this paper.

\section{Acknowledgement}

SdB and JH acknowledge funding from an Utrecht University Pathways to Sustainability Acceleration Grant. NW acknowledges funding from NWO 016.Veni.181.049. NvU acknowledges funding from Mistra Geopolitics Research Programme. HB acknowledges funding from the European Research Council via grant no. 648291. We would like to acknowledge the participants of a workshop in March 2020 to kick-start the project this article is a product of: Stijn van Weezel (Radboud University Nijmegen), Ruben Dahm (Deltares), Karin Meijer (Deltares), Joost Knoop (PBL Netherlands Environmental Assessment Agency), Ben ten Brink (PBL Netherlands Environmental Assessment Agency) and Rens van Beek (Utrecht University). We would also like to acknowledge the helpful and constructive review by two anonymous reviewers.

\section{References}

Ahmadalipour, A., Moradkhani, H., Castelletti, A., Magliocca, N., 2019. Future drought risk in Africa: Integrating vulnerability, climate change, and population growth. Sci. Total Environ. 662, 672-686.

Andrijevic, M., Cuaresma, J.C., Muttarak, R., Schleussner, C.-F., 2020. Governance in socioeconomic pathways and its role for future adaptive capacity. Nat. Sustainability 3, 35-41.

Blattman, C., Miguel, E., 2010. Civil war. J. Econ. Lit. 48, 3-57.

Bowlsby, D., Chenoweth, E., Hendrix, C., Moyer, J.D., 2019. The future is a moving target: predicting political instability. Brit. J. Polit. Sci. 1-13.

Buhaug, H., Vestby, J., 2019. On growth projections in the shared socioeconomic pathways. Global Environ. Polit. 19, 118-132.

Busby, J.W., Smith, T.G., Krishnan, N., 2014. Climate security vulnerability in Africa mapping 3.0. Polit. Geogr. 43, 51-67.

Byers, E., Gidden, M., Leclère, D., Balkovic, J., Burek, P., Ebi, K., Greve, P., Grey, D. Havlik, P., Hillers, A., Johnson, N., Kahil, T., Krey, V., Langan, S., Nakicenovic, N., Novak, R., Obersteiner, M., Pachauri, S., Palazzo, A., Parkinson, S., Rao, N.D., Rogelj, J., Satoh, Y., Wada, Y., Willaarts, B., Riahi, K., 2018. Global exposure and vulnerability to multi-sector development and climate change hotspots. Environ. Res. Lett. 13, 055012.

Cederman, L.E., 1997. Emergent Actors in World Politics: How States and Nations Develop and Dissolve. Princeton University Press.

Cederman, L.E., Gleditsch, K.S., Buhaug, H., 2013. Inequality, Grievances, and Civil War. Cambridge University Press.

Cederman, L.E., Weidmann, N.B., 2017. Predicting armed conflict: time to adjust our expectations? Science $355,474-476$.

Colaresi, M., Mahmood, Z., 2017. Do the robot: Lessons from machine learning to improve conflict forecasting. J. Peace Res. 54, 193-214.

Cramer, C., 2006. Civil war is not a stupid thing: Accounting for violence in developing countries. Hurst London.

Dellink, R., Chateau, J., Lanzi, E., Magné, B., 2017. Long-term economic growth projections in the shared socioeconomic pathways. Global Environ. Change 42, 200-214.

Demmers, J., 2017. Theories of Violent Conflict. Routledge, Abingdon and New York.

Department of Defence USA, 2019. Report on Effects of a Changing Climate to the Department of Defense. Office of the Under Secretary of Defense for Acquisition and Sustainment, Washington DC.

Doelman, J.C., Stehfest, E., Tabeau, A., van Meijl, H., Lassaletta, L., Gernaat, D.E.H.J. Hermans, K., Harmsen, M., Daioglou, V., Biemans, H., van der Sluis, S., van Vuuren, D.P., 2018. Exploring SSP land-use dynamics using the IMAGE model: Regional and gridded scenarios of land-use change and land-based climate change mitigation. Global Environ. Change 48, 119-135.

Eprs, 2020. Peace, justice and strong institutions. Members' Research Service. European Parliamentary Research Service.

Eriksen, S., Aldunce, P., Bahinipati, C.S., Martins, R.D.A., Molefe, J.I., Nhemachena, C., O’brien, K., Olorunfemi, F., Park, J., Sygna, L., 2011. When not every response to climate change is a good one: identifying principles for sustainable adaptation. Climate Dev. 3, 7-20.

European Commission, 2019. EU Conflict Early Warning System: Objectives, Process and Guidance for Implementation.

Gartzke, E., 1999. War is in the error term. Int. Org. 53, 567-587.

Gates, S., Hegre, H., Nygård, H.M., Strand, H., 2012. Development consequences of armed conflict. World Dev. 40, 1713-1722.

Gemenne, F., Alex, B., Baillat, A., 2020. Implications of climate change on defence and security in the south pacific by 2030. French Ministry of Defence, Directorate General for International Relations .... 
Gilmore, E., Hegre, H., Olafsdottir, G., Petrova, K. 2021 unpublished. The 'conflict trap' reduces economic growth in the shared socioeconomic pathways. Global Environ. Change, Unpublished manuscript.

Hegre, H., Allansson, M., Basedau, M., Colaresi, M., Croicu, M., Fjelde, H., Hoyles, F., Hultman, L., Högbladh, S., Jansen, R., 2019. ViEWS: a political violence earlywarning system. J. Peace Res. 56, 155-174.

Hegre, H., Buhaug, H., Calvin, K.V., Nordkvelle, J., Waldhoff, S.T., Gilmore, E., 2016. Forecasting civil conflict along the shared socioeconomic pathways. Environ. Res. Lett. 11, 054002.

Hegre, H., Karlsen, J., Nygård, H.M., Strand, H., Urdal, H., 2013. Predicting armed conflict, 2010-2050. Int. Stud. Quart. 57, 250-270.

Hegre, H., Nygård, H.M., Landsverk, P., 2021. Can we predict armed conflict? How the first 9 years of published forecasts stand up to reality. Int. Stud. Quart.

Hegre, H., Sambanis, N., 2006. Sensitivity analysis of empirical results on civil war onset. J. Conflict Resolut. 50, 508-535.

Hoch, J., De Bruin, S.P., Von Uexkull, N., Buhaug, H., Van Beek, R., Wanders, N., 2021. Projecting armed conflict risk in Africa towards 2050 along the Shared Socioeconomic Pathways: a machine learning approach. EarthArxiv.

Hughes, B.B., Josh, D.K., Moyer, J.D., Sisk, T.D., Solorzano, J.R., 2014. Strengthening Governance Globally: Forecasting the Next 50 Years. Routledge.

IPCC, 2018. Global Warming of $1.5^{\circ} \mathrm{C}$. An IPCC Special Report on the impacts of global warming of $1.5^{\circ} \mathrm{C}$ above pre-industrial levels and related global greenhouse gas emission pathways, in the context of strengthening the global response to the threat of climate change, sustainable development, and efforts to eradicate poverty. In: Masson-Delmotte, V., Zhai, P., Pörtner, H.-O., Roberts, D., Skea, J., Shukla, P.R., Pirani, A., Moufouma-Okia, W., Péan, C., Pidcock, R., Connors, S., Matthews, J.B.R., Chen, Y., Zhou, X., Gomis, M.I., Lonnoy, E., Maycock, T., Tignor, M., Waterfield, T. (Eds.).

IPCC, 2019. Climate Change and Land: an IPCC special report on climate change, desertification, land degradation, sustainable land management, food security, and greenhouse gas fluxes in terrestrial ecosystems. In: Shukla, P.R., J.S., Calvo Buendia, E., Masson-Delmotte, V., Pörtner, H.-O., Roberts, D.C., Zhai, P., Slade, R., Connors, S., Van Diemen, R., Ferrat, M., Haughey, E., Luz, S., Neogi, S., Pathak, M., Petzold, J., Portugal Pereira, J., Vyas, P., Huntley, E., Kissick, K., Belkacemi, M., Malley, J., (Eds.).

Jones, L., Champalle, C., Chesterman, S., Cramer, L., Crane, T.A., 2017. Constraining and enabling factors to using long-term climate information in decision-making. Climate Policy 17, 551-572.

Joshi, D.K., Hughes, B.B., Sisk, T.D., 2015. Improving governance for the post-2015 sustainable development goals: scenario forecasting the next 50 years. World Dev. 70, 286-302.

Koubi, V., 2019. Climate change and conflict. Ann. Rev. Polit. Sci. 22, 343-360.

Landholm, D.M., Pradhan, P., Kropp, J.P., 2019. Diverging forest land use dynamics induced by armed conflict across the tropics. Global Environ. Change 56, 86-94.

Lucarelli, S., Ceccorulli, M., Fassi, E., Lenzi, V., Moro, F.N., Villa, M., Casprini, F., Castelli, E., Chatagnier, T., Kavakli, K.C., 2014. PREDICT - Projections and Relevant Effects of Demographic Implications, Changes, and Trends. NATO HQ, Brussels.

Mach, K.J., Kraan, C.M., 2021. Science-policy dimensions of research on climate change and conflict. J. Peace Res. 0022343320966774.

Mach, K.J., Kraan, C.M., Adger, W.N., Buhaug, H., Burke, M., Fearon, J.D., Field, C.B., Hendrix, C.S., Maystadt, J.-F., O'loughlin, J., 2019. Climate as a risk factor for armed conflict. Nature 571, 193-197.
Mahmoud, M., Liu, Y., Hartmann, H., Stewart, S., Wagener, T., Semmens, D., Stewart, R., Gupta, H., Dominguez, D., Dominguez, F., 2009. A formal framework for scenario development in support of environmental decision-making. Environ. Modell. Software 24, 798-808.

Maier, H.R., Guillaume, J.H.A., Van Delden, H., Riddell, G.A., Haasnoot, M., Kwakkel, J. H., 2016. An uncertain future, deep uncertainty, scenarios, robustness and adaptation: How do they fit together? Environ. Modell. Software 81, 154-164.

Molnar, C., 2021. Interpretable machine learning: A guide for making black box models explainable, Leanpub.

Muchlinski, D., Siroky, D., He, J., Kocher, M., 2016. Comparing random forest with logistic regression for predicting class-imbalanced civil war onset data. Polit. Anal. 87-103.

Muhonen, R., Benneworth, P., Olmos-Peñuela, J., 2020. From productive interactions to impact pathways: Understanding the key dimensions in developing SSH research societal impact. Res. Eval. 29, 34-47.

Muzalevsky, R., 2017. Strategic Landscape, 2050: Preparing the US Military for New Era Dynamics. US Army War College Press Carlisle United States.

Rao, N., Sauer, P., Gidden, M., Riahi, K., 2019. Income inequality projections for the Shared Socioeconomic Pathways (SSPs). Futures 105, 27-39.

Raskin, P., Monks, F., Ribeiro, T., Vuuren, D.V., Zurek, M., 2005. Global scenarios in historical perspective. Ecosystems and human well-being. Island Press, Washington DC.

Rigaud, K.K., De Sherbinin, A., Jones, B., Bergmann, J., Clement, V., Ober, K., Schewe, J., Adamo, S., Mccusker, B. \& Heuser, S., 2018. Groundswell: Preparing for Internal Climate Migration. World Bank, Washington DC.

Schillinger, J., Özerol, G., Güven-Griemert, Ș., Heldeweg, M., 2020. Water in war: Understanding the impacts of armed conflict on water resources and their management. Wiley Interdis. Rev.: Water 7, e1480.

Taleb, N.N., 2010. The Black Swan: the impact of the highly improbable. A Random House Trade Paperback, New York.

UNSC, 2017. Security Council resolution 2349 [on the situation in the Lake Chad Basin region]. United Nation Security Council, New York.

Van Beek, L., Hajer, M., Pelzer, P., Van Vuuren, D., Cassen, C., 2020. Anticipating futures through models: the rise of Integrated Assessment Modelling in the climate sciencepolicy interface since 1970. Global Environ. Change 65, 102191.

Van Meijl, H., Shutes, L., Valin, H., Stehfest, E., Van Dijk, M., Kuiper, M., Tabeau, A., Van Zeist, W.-J., Hasegawa, T., Havlik, P., 2020. Modelling alternative futures of global food security: Insights from FOODSECURE. Global Food Security 25, 100358.

Visser, H., De Bruin, S.P., Martens, A., Knoop, J., Ligtvoet, W., 2020. What users of global risk indicators should know. Global Environ. Change 62, 102068.

Von Uexkull, N., Buhaug, H., 2021. Security implications of climate change: a decade of scientific progress. J. Peace Res. 58, 3-17.

WANEP, 2021. West Africa Early Warning and Early Response Network (WARN) [Online]. West Africa Network for Peacebuilding. Available: https://wanep.org/wa nep/warn/ [Accessed 10 February 2021].

Witmer, F.D., Linke, A.M., O'loughlin, J., Gettelman, A., Laing, A., 2017. Subnational violent conflict forecasts for sub-Saharan Africa, 2015-65, using climate-sensitive models. J. Peace Res. 54, 175-192.

WPS. 2021. Water Peace and Security Tool [Online]. Water Peace Security Partnership Available: https://waterpeacesecurity.org/ [Accessed 24 February 2021].

Xu, C., Kohler, T.A., Lenton, T.M., Svenning, J.-C., Scheffer, M., 2020. Future of the human climate niche. Proc. Natl. Acad. Sci. 117, 11350-11355. 